\title{
Using QR Codes to Connect Patients to Health Information
}

Warren C. Hayes, MD

Ann Fam Med 2017;15:275. https://doi.org/10.1370/afm.2067.

\section{THE INNOVATION}

Patients are engaged with their digital devices at nearly every office visit, texting, checking email, catching up on news, or gaming. I wanted to take advantage of the attention patients pay to their smartphones and turn it into an engagement opportunity. I developed QR (Quick Response) codes for online information about common health issues both to entertain and to educate. This gets the information I want patients to have directly onto their digital devices where they can access it as easily as their other digital content.

\section{WHO \& WHERE}

We are a rural 5-provider family medicine clinic in Southwest lowa.

\section{HOW}

We generate the QR codes we want, print them with short explanations of what the codes will link to, and display them in the waiting room and elsewhere. While waiting, a patient can scan any of the codes with his or her wireless device and immediately load a digital resource about the topic of interest, be it back pain, smoking cessation, URI, or any of a variety of other topics. Patient education is also linked with QR codes, so the patient can scan a code for information germane to the reason for his or her visit and have educational materials available to read later. We change some of the codes displayed seasonally, for instance posting a code for information on influenza in the winter and sunburn in the summer (Supplemental Figure 1). The possibilities are endless. A mother can scan a code for quick access to age/weight acetaminophen dosing (Figure). Parents and kids waiting in the exam room can scan codes to learn about the equipment they see around them (Supplemental Figure 2). One code could hold the office address, phone numbers and provider information-or just link to the office website.

Conflicts of interest: author reports none.

\section{CORRESPONDING AUTHOR}

Warren C. Hayes, MD

Physicians Clinic - Red Oak

1400 Senate Ave Ste 105

Red Oak, IA 51566

warren.hayes@nmhs.org

\section{Figure: QR codes like this one, which encodes the web address for a table of acetaminophen dosing, can be generated easily. An app on the patient's smartphone can then read the code and load the web page immediately.}

Scan here to learn more

Acetaminophen dosing for children 2 yrs and older

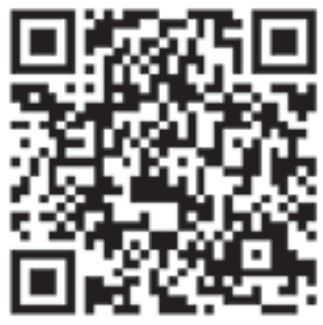

The technology to implement this is easy to master and available online. You can generate a QR code for a web page by entering the web address into a field on any of several QR-code generating websites, usually for free. You can then download the code image and have it available for inclusion in posters or other documents. Many patients will already have QR-code reading apps in their phones; any who don't can download one free of charge from the online store for the appropriate operating system. If you don't already have websites you find useful for patient health information, https://www.cdc.gov and https:// healthfinder.gov are good. You can, of course, also create your own web pages of health information and create QR codes for them if you have the means. Our office has guest WiFi, so patients' data plans are usually not affected by their scanning QR codes. However, I do post that data plan charges may apply if QR codes are read in the office. Once a code is scanned, the patient can bookmark the resulting page for later reference or at least find it in the browser history of the QR reader app.

\section{LEARNING}

Response to this innovation has been positive. Staff members enjoy the idea that patients aren't just wasting time but learning about health topics while on their phones. Patients are happy not to turn off their devices in the office. Grade school children have no problem with the concept and they are adept at teaching their parents how to scan a code.

Key words: patient health information; online systems; cell phones

Supplemental Figures $1 \& 2$ are available at http://www.Ann FamMed.org/content/15/3/275/suppl/DC1/. 